\title{
DETEKSI DINI KANKER PAYUDARA DI KELURAHAN LIMBUNGAN KECAMATAN RUMBAI PESISIR
}

\author{
Siti Qomariah $^{1)}$, Wiwi Sartika ${ }^{2)}$, Sellia Juwita ${ }^{3)}$ \\ ${ }^{1-3)}$ Universitas Abdurrab \\ Surel: siti.qomariah@univrab.ac.id
}

\begin{abstract}
Background: Currently breast cancer is a serious threat in the world. Breast cancer is a major problem in Indonesia and in other countries. Breast cancer in Indonesia is in second place as the most common cancer found in women after cervical cancer. Around $48 \%$ incidence of breast cancers occur in women over the age of 65 years and $30 \%$ in women aged over 70 years. Only about one-third of cases diagnosed in premenopausal women. Objective: Provide health education / knowledge to women Women Eligible to be able to apply and implement early detection of breast cancer in everyday life. Method: Counseling About the early detection of breast cancer. Result: Activity counseling and early detection of breast cancer with the technique of breast selfexamination (BSE) which was held on Saturday 19 November 2016 mothers mosque committees limbungan district Rumbai Pekanbaru. The number of participants who attended the counseling activities and early detection of breast cancer with the technique of breast self-examination (BSE) is attended by mothers mosque committeesas many as 47 people. Conclusion: Peoses implementation of outreach and early detection of breast cancer with the technique of breast self-examination (BSE) runs well and smoothly. Mothers mosque committeeswere very enthusiastic and eager to follow the activities of this devotion.
\end{abstract}

Keywords: Counseling, early detection of breast cancer

\begin{abstract}
ABSTRAK
Latar Belakang:Saat ini kanker payudara menjadi ancaman yang serius di dunia. Kanker payudara merupakan masalah besar di indonesia maupun di negara lain. Kanker payudara di indonesia berada di urutan kedua sebagai kanker yang paling sering ditemukan pada perempuan setelah kanker leher rahim. Sekitar $48 \%$ insiden kanker payudara terjadi pada perempuan berusia lebih dari 65 tahun dan 30\% pada perempuan berusia lebih dari 70 tahun. Hanya sekitar sepertiga kasus yang terdiagnosis pada perempuan premenopause. Tujuan: Memberikan pendidikan kesehatan / pengetahuan kepada wanita Wanita Usia Subur agar dapat mengaplikasikan serta menerapkan cara deteksi dini kanker payudara dalam kehidupan sehari-hari. Metode: Dengan memberikan penyuluhan Tentang deteksi dini kanker payudara. Hasil: Kegiatan penyuluhan tentang deteksi dini kanker payudara dengan teknik pemeriksaan payudara sendiri (SADARI) yang telah dilaksanakan pada hari sabtu tanggal 19 November 2016 di acara ibu-ibu majlis ta'lim Kel. Limbungan Kec Rumbai Pekanbaru. Jumlah peserta yang hadir dalam kegiatan penyuluhan dan deteksi dini kanker payudara dengan teknik pemeriksaan payudara sendiri (SADARI) dihadiri oleh ibu-ibu majlis ta'lim sebanyak 47 orang. Kesimpulan: Peoses pelaksanaan penyuluhan dan deteksi dini kanker payudara dengan teknik pemeriksaan payudara sendiri (SADARI) berjalan dengan baik dan lancar. Ibu-ibu majlis ta'lim sangat antusias dan bersemangat dalam mengikuti kegiatan pengabdian ini.
\end{abstract}

Kata Kunci:Penyuluhan, Deteksi dini kanker payudara 


\section{PENDAHULUAN}

Kanker payudara adalah keganasan pada sel-sel yang terdapat pada jaringan payudara, bisa berasal dari komponen kelenjarnya (epitel saluran maupun lobulusnya) maupun komponen selain kelenjar seperti jaringan lemak, pembuluh darah dan persarafan jaringan payudara (Nurcahyo, J. 2010).

Menurut data World Health Organization (WHO) tahun 2013, insidens kanker meningkat dari 12,7 juta kasus tahun 2008 menjadi 14,1 juta kasus tahun 2012. Sedangkan jumlah kematian meningkat dari 7,6 juta orang tahun 2008 menjadi 8,2 juta pada tahun 2012. Kanker menjadi penyebab kematian nomor 2 di dunia sebesar $13 \%$ setelah penyakit kardiovaskular.

Kanker payudara merupakan masalah besar di indonesia maupun di negara lain. Kanker payudara di indonesia berada di urutan kedua sebagai kanker yang paling sering ditemukan pada perempuan setelah kanker leher rahim. Sekitar $48 \%$ insiden kanker payudara terjadi pada perempuan berusia lebih dari 65 tahun dan $30 \%$ pada perempuan berusia lebih dari 70 tahun. Hanya sekitar sepertiga kasus yang terdiagnosis pada perempuan premenopause, namun kanker payudara yang terdiagnosis pada usia muda menunjukkan gambaran klinikopatologi yang lebih agresif dengan angka harapan hidup yang lebih rendah dibandingkan dengan kelompok usia yang lebih tua.

Pendeteksian dini mengenai gejala kanker payudara akan memberikan tingkat kesembuhan yang lebih tinggi pada penderita. Apabila kanker telah ditemukan pada stadium awal, penyembuhan yang dilakukan akan lebih mudah dan kemungkinan sembuh juga lebih besar. Hal ini karena kanker belum menyebar ke daerah bagian organ lainnya. pengenalan gejala-gejala kanker payudara sebaiknya dikenali oleh semua orang untuk mencegah terlambatnya seseorang mengenali gejala kanker yang dideritanya. Dengan mengenali gejala-gejala kanker payudara,dapat kemungkinan terserang kanker payudara atau tidak (Martyani, Dwiakhid. 2009).

Penyebab kurangnya tindakan pencegahan yang dilakukan oleh masyarakat dikarenakan masih rendahnya pemahaman masyarakat tentang kanker payudara, sehingga masyarakat yang datang berobat ke dokter kebanyakan datang dengan keadaan stadium lanjut dan sulit untuk diobati. Inilah yang menjadi salah satu penyabab kenapa dari tahun ketahun angka mortalitas kanker payudara semakin tinggi (Martyani, Dwiakhid. 2009).

Penyuluhan kesehatan merupakan revitalisasi pendidikan kesehatan pada masa lalu, dimana dalam konsep penyuluhan kesehatan bukan hanya proses penyadaran masyarakat dalam bidang kesehatan saja, melainkan juga upaya bagaimana mampu menjembatani adanya perubahan perilaku seseorang (Kumalasari, 2012).

Tujuan dari pengabdian masyarakat ini adalah mensosialisasikan bagaimana cara deteksi dini kanker payudara serta memberikan pendidikan kesehatan / pengetahuan kepada wanita Usia Subur agar dapat menerapkan cara deteksi dini kanker payudara dalam kehidupan sehari-hari. 


\section{METODE PENERAPAN}

Pengabdian ini dilaksanakan dalam bentuk penyuluhan dan pelatihan selama 2 hari kepada ibu-ibu majlis ta'lim di Kelurahan Limbungan Kecamatan Rumbai Pesisir. Dalam pelatihan ini menggunakan metode pelatihan yang diantaranya diawali penyuluhan materi, diskusi, serta demonstrasi.

\section{HASIL DAN PEMBAHASAN}

Kegiatan pengabdian kepada masyarakat ini telah dilaksanakan dengan metode pelatihan, dan demonstrasi kepada ibu-ibu majlis ta'lim di Kelurahan Limbungan Kecamatan Rumbai Pesisir pada tanggal 19 November 2016 dengan rincian waktu:

13.00-15.00 : Pelatihan dan penyuluhan pada ibu-ibu majlis ta'lim

15.00-16.30 : Evaluasi hasil dari demonstrasi pada ibu-ibu majlis ta'lim (peserta pelatihan diminta untuk mempraktekkan secara mandiri).

Kehadiran peserta saat penyuluhan berjumlah 47 orang, Pelaksanaan kegiatan pengabdian sesuai dengan waktu yang dijadwalkan, Penyampaian materi sesuai dengan apa yang direncanakan. Pada saat pelaksanaan pelatihan, Alhamdulillah ibu-ibu yang hadir sangat interaktif dan antusias dengan kegiatan ini.

Pelaksanaan kegiatan mencakup beberapa komponen, diantaranya :

1. Kehadiran ibu-ibu majlis ta'lim dari awal kegiatan sampi dengan selesai

2. Pelaksanaan kegiatan pengabdian masyarakat sesuai dengan waktu yang dijadwalkan

3. Penyampaian materi sesuai dengan yang direncanakan

4. Antusias para peserta pelatihan sangat baik

Dari komponen diatas terlihat, sangat baiknya animo ibu-ibu majlis ta'lim dalam menerima pelatihan Deteksi Dini Kanker Payudara yang dilaksanakan. Pelaksanaan kegiatan pengabdian ini dengan menggunakan metode pelatihan, penyuluhan dan demonstrasi sangat baik untuk memberikan pengetahuan dan keterampilan yang berkaitan dengan pendidikan kesehatan kepada masyarakat, ini dibuktikan dengan banyaknya ibu-ibu majlis ta'lim yang hadir yang ingin mencobakan langsung saat praktek pelaksanaan teknik deteksi dini kanker payudara tersebut. Salah satu dari peserta pelatihan, kami jumpai dengan diagnose kanker payudara stadium 4 dan sudah berobat ke Rumah Sakit. Tapi terkait surat menyurat untuk kelengkapan tindakan operasi, maka sampai pada hari pelatihan, ibu tersebut belum mendapatkan tindakan operasi. Kasus kanker payudara pada ibu ini salah satunya dikarenakan oleh tidak terdeteksinya secara dini tanda dan gejala penyakit kanker payudara. Oleh sebab itu, para peserta pelatihan (ibu-ibu majlis ta'lim) sangat senang dengan kegiatan yang telah kami laksanakan ini. Peserta menyebutkan sangat bermanfaat sekali pelatihan dan penyuluhan yang telah dilaksanakan.

Gambar 1. 
Jurnal Pengabdian Masyarakat

vol.1 no. 1 Oktober 2017

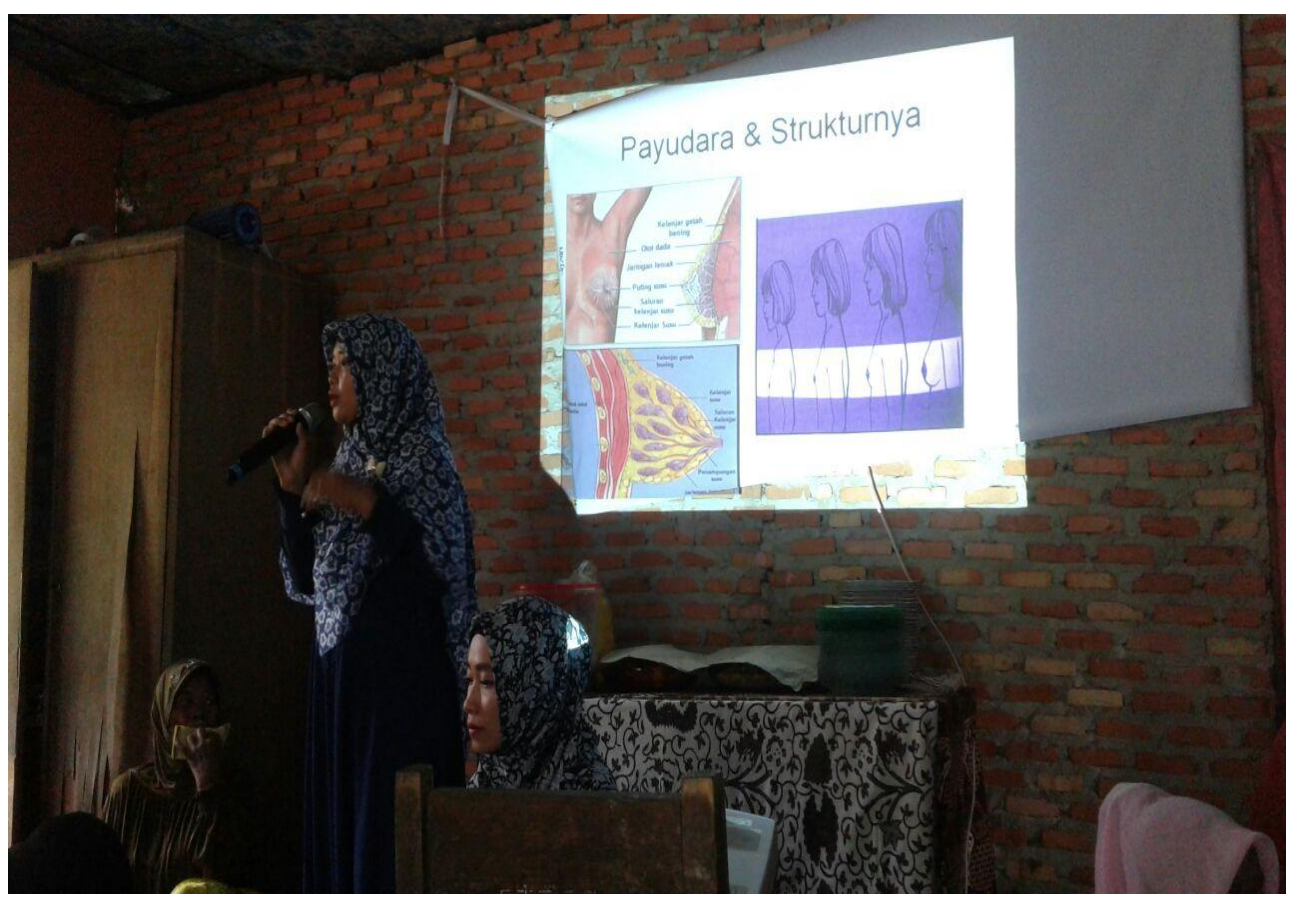

Gambar 2

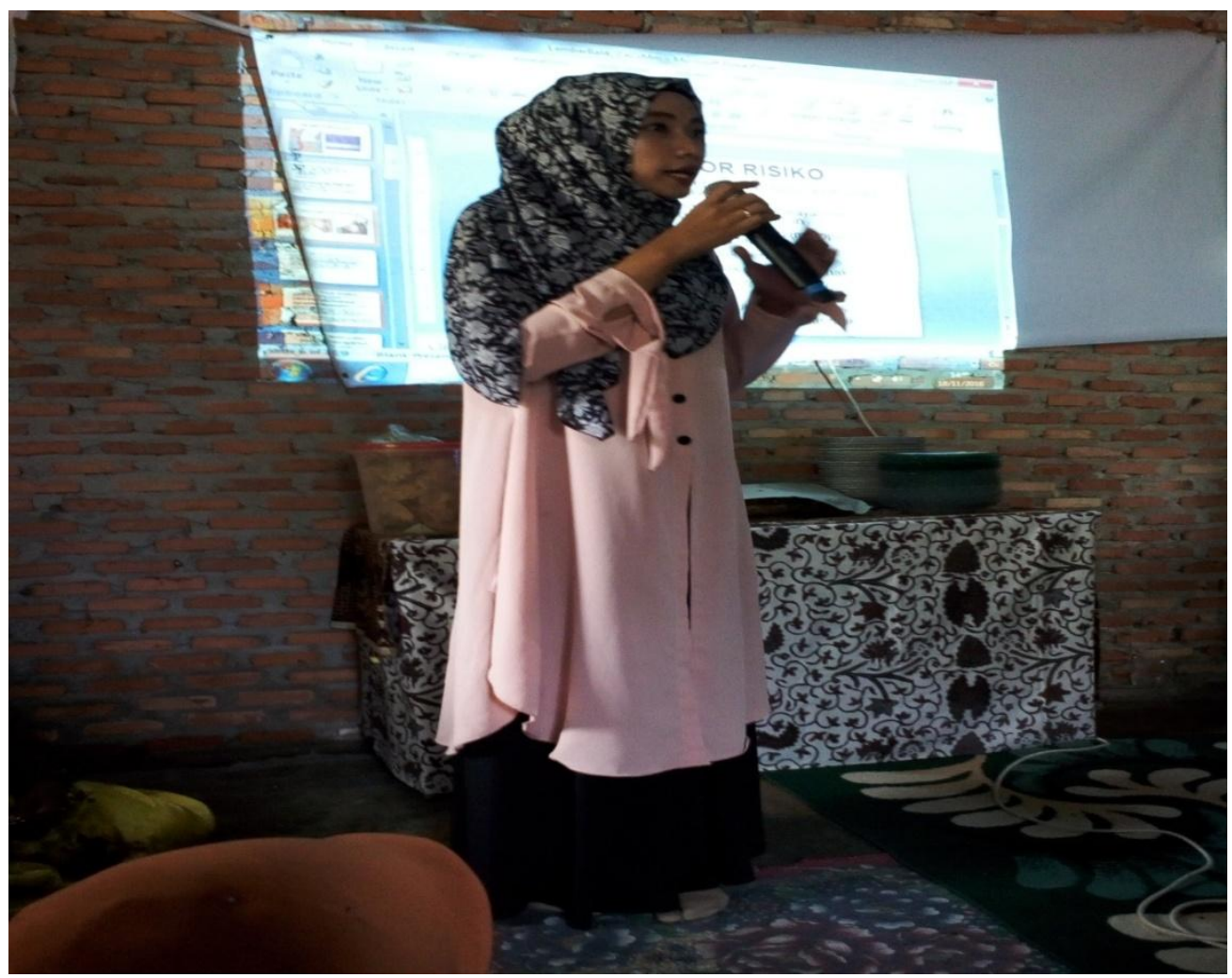

Gambar 3 


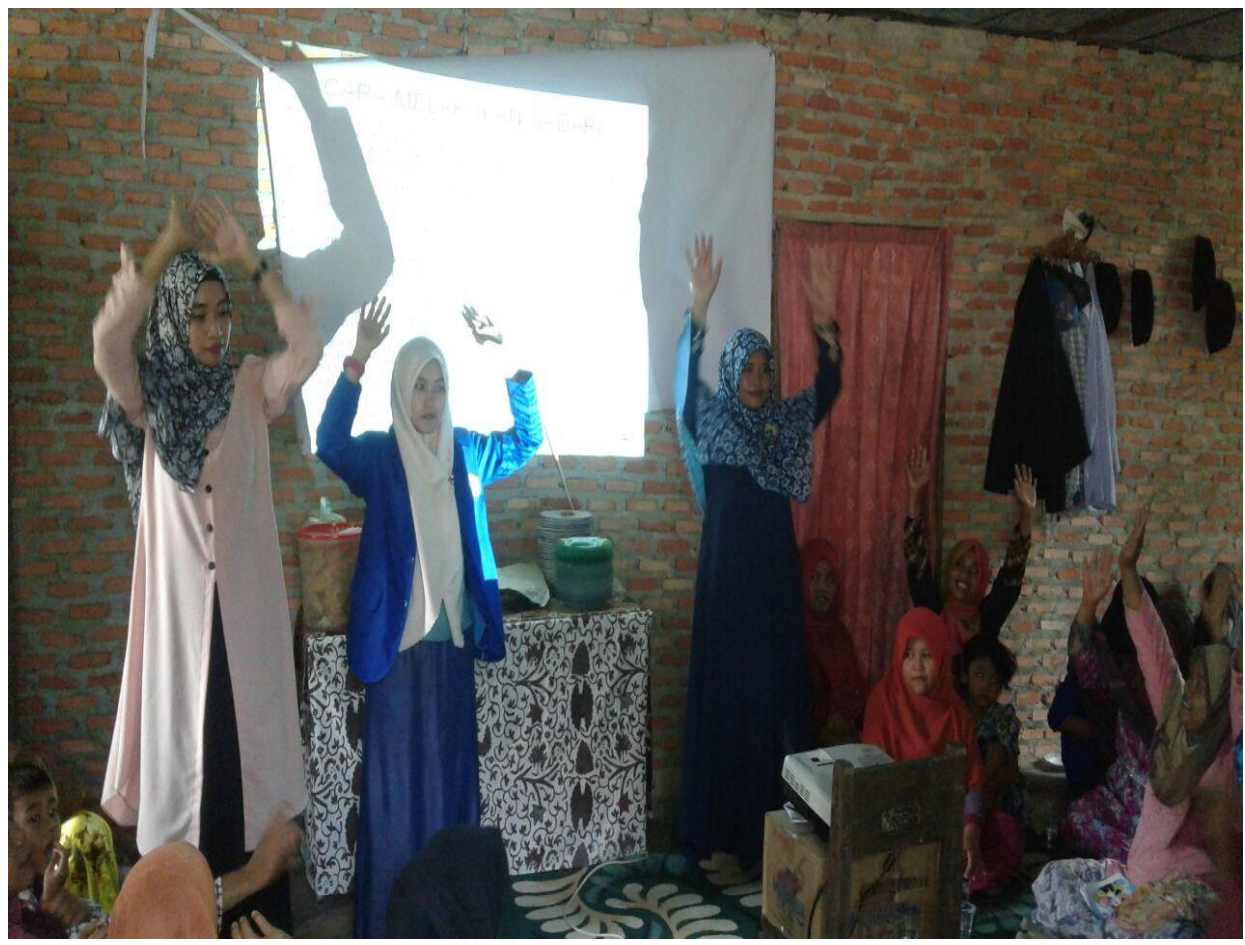

Gambar 4

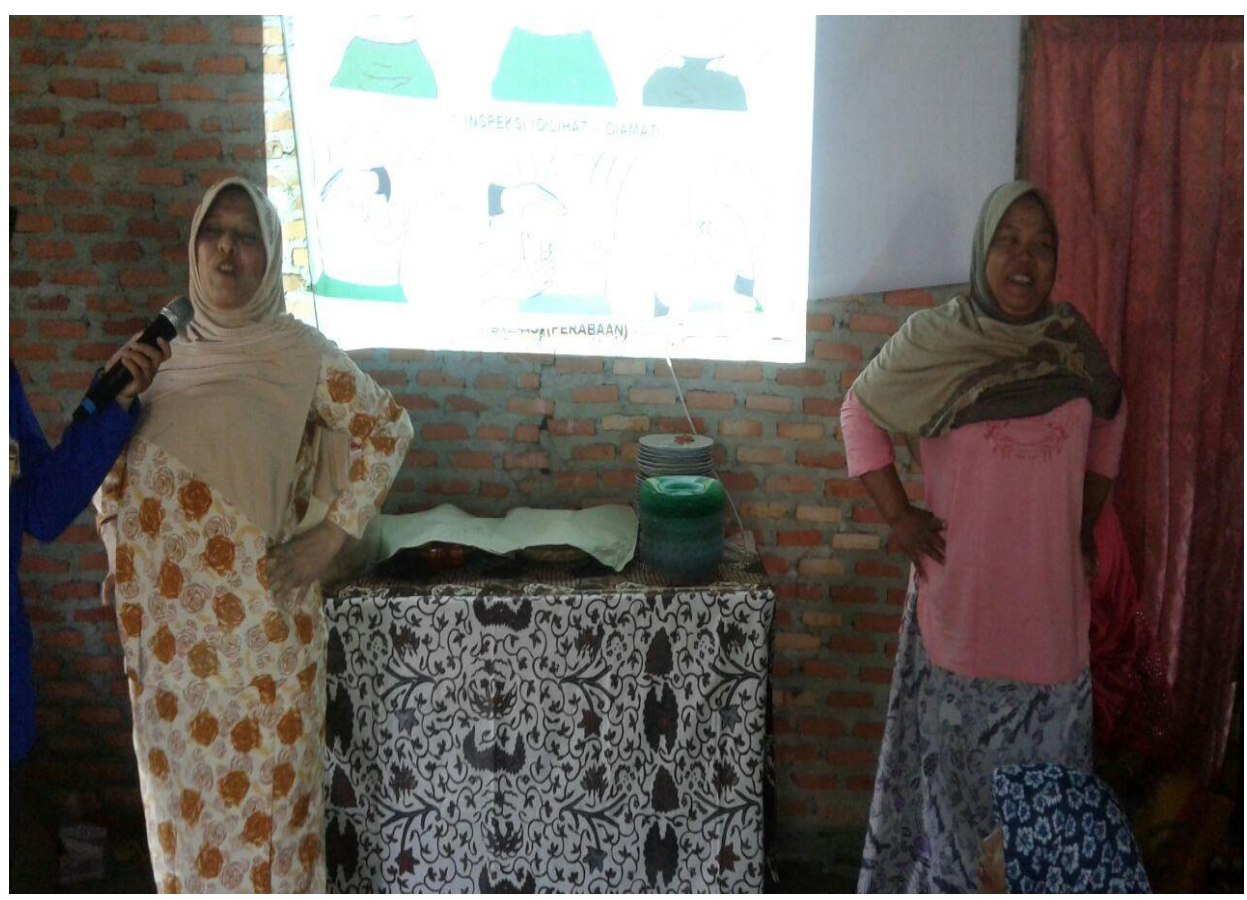

Gambar 5 
Jurnal Pengabdian Masyarakat

vol.1 no.1 Oktober 2017

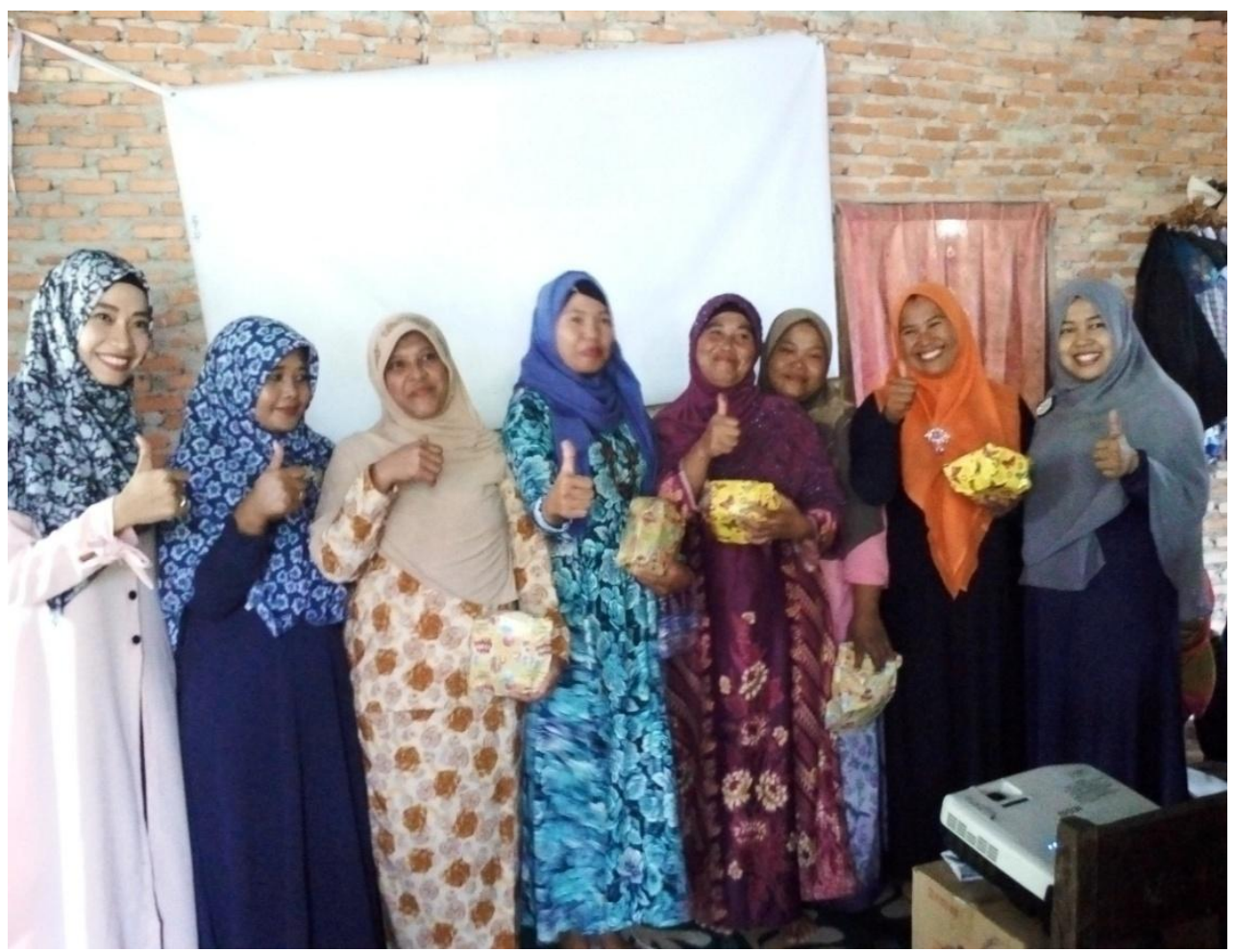

Gambar 6

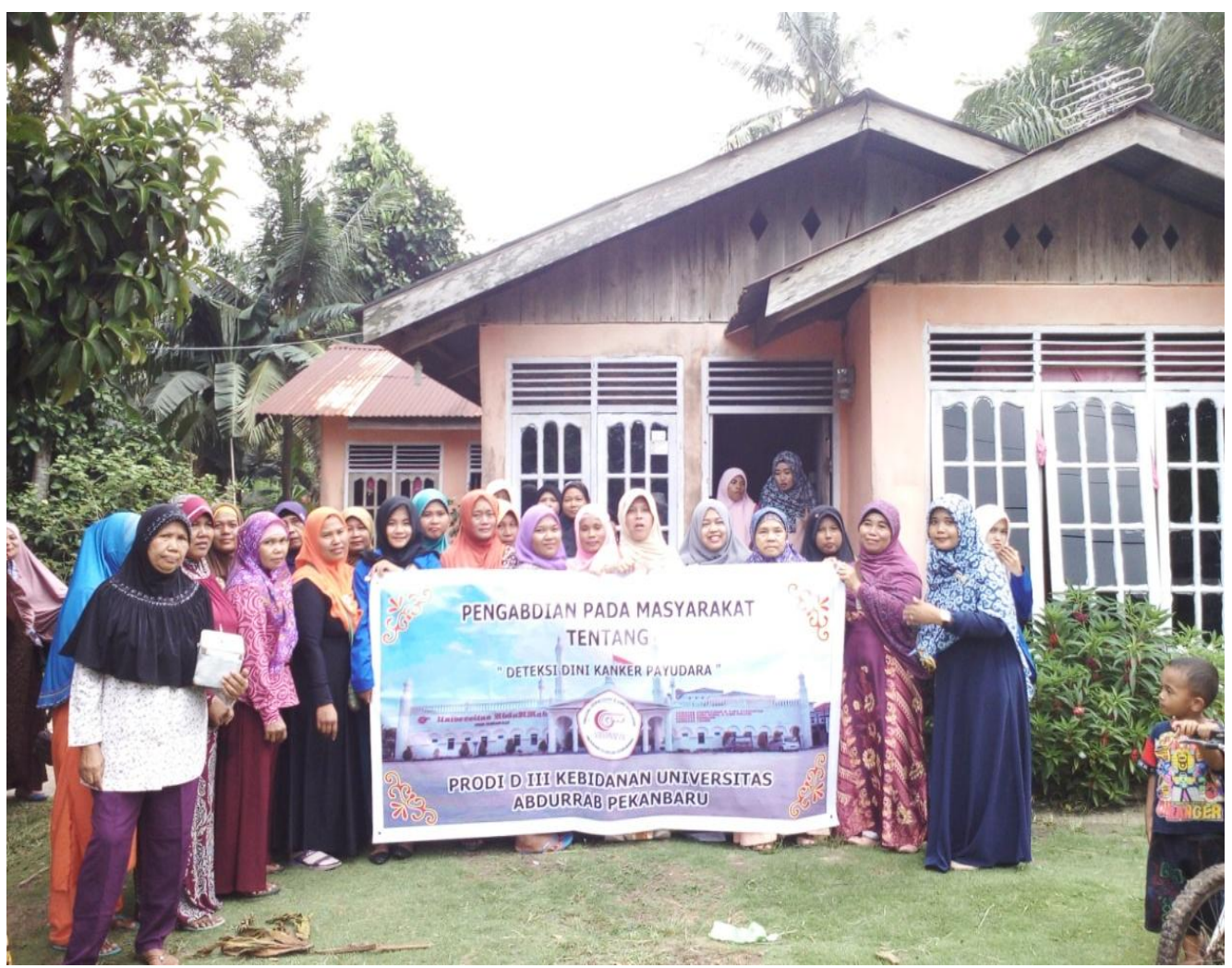

Gambar 7 


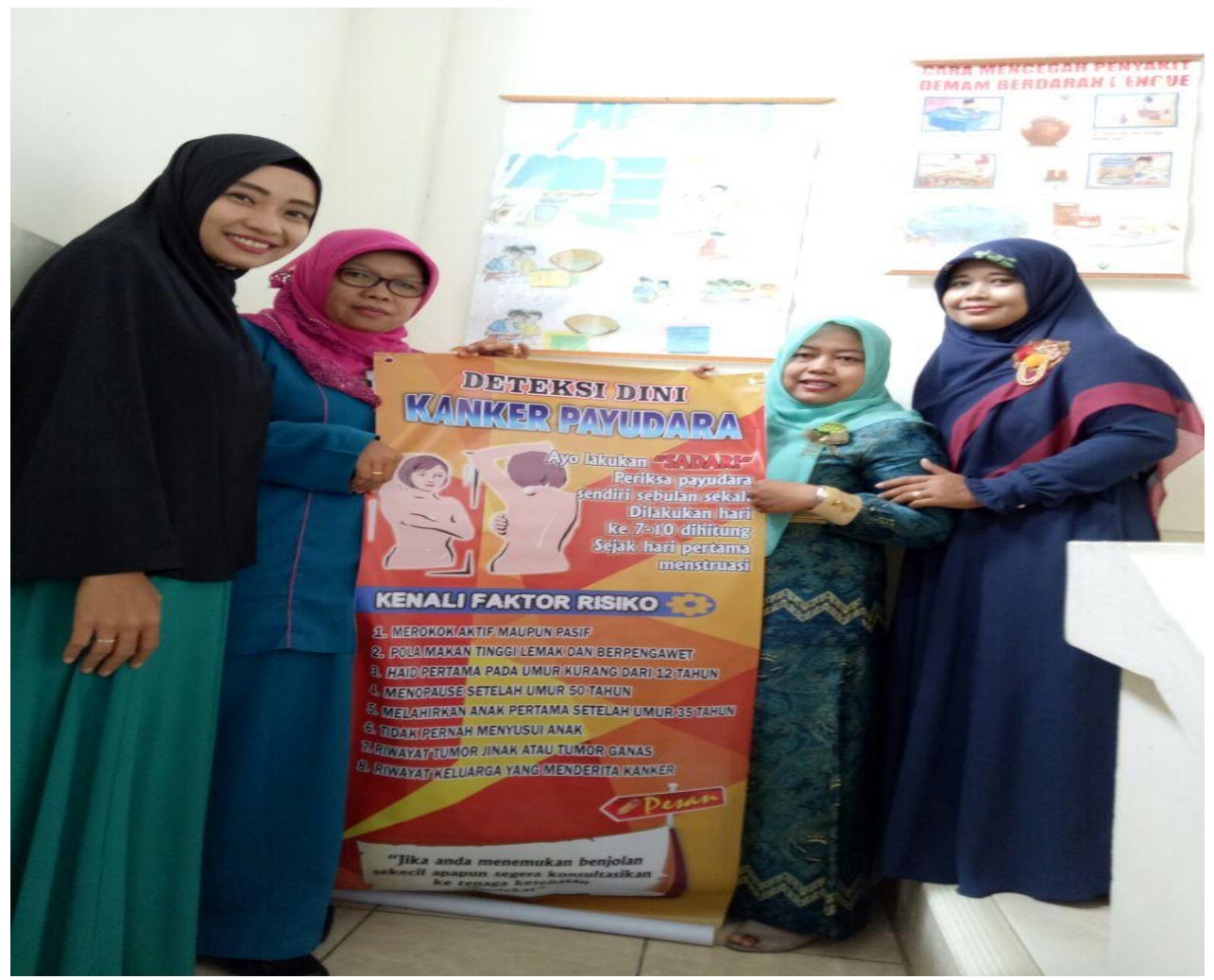

\section{KESIMPULAN}

Kegiatan sosialisasi ini dilakukan selama beberapa kali kepada ibu-ibu majlis ta'lim yang berada di Kelurahan Limbungan dengan menyebarkan brosur dan pemasangan spanduk, untuk penyuluhannya satu kali, dan terakhir kunjungan ke Kelurahan memberikan kenang-kenangan serta pemasangan Banner tentang SADARI. Kegiatan penyuluhan ini berjalan dengan baik dan lancar sesuai yang dijadwalkan dan Pada saat kegiatan banyak pra ibu-ibu yang antusias terhadap tema ini, ini membuktikan para ibu-ibu majlis ta'lim sangat peduli dengan masalah reproduksi terutama tentang kanker payudara.

Untuk mendeteksi secara dini kanker payudara, pemeriksaan payudara sendiri sebaiknya pemeriksaan payudara dilakukan sebulan sekali. Dengan menggunakan teknik SADARI. Para wanita yang sedang haid sebaiknya melakukan pemeriksaan pada hari ke-5 sampai ke-10 dari hari pertama haid, ketika payudara sedang mengendur dan terasa lebih lunak. Untuk kegiatan Pengabdian Masyarakat selanjutnya di harapkan bisa melakukan Pelatihan SADARI dengan menggunakan manekin payudara, sehingga setiap peserta dapat mencoba untuk melakukan SADARI sendiri, serta mengenali keadaan payudara normal

\section{DAFTAR PUSTAKA}


1. Dyayadi, M.T. 2009. Pembunuh Ganas dan di ditakuti itu bernama Kanker. Jakarta: Riz'ma.

2. Kumalasari, I., dan Iwan, A. 2012. "Kesehatan Reproduksi" Palembang: Salemba Medika

3. Martyani, Dwiakhid. 2009. Hubungan Pengetahuan dan Sikap tentang SADARI dengan Perilaku SADARI (Pemeriksaan Payudara Sendiri) di RW VIII Kelurahan Warungboto Kecamatan Umbulharjo D.I.Yogyakarta Tahun 2008.

4. Nurcahyo, J. 2010. Bahaya Kanker Rahim dan Payudara. Jakarta: Wahana Totalita Publisher.

5. Rasjidi,I.2009.Deteksi Dini dan Pencegahan Kanker Pada Wanita.Jakrta:Sagung Seto.

6. Setiant, E. 2009. Waspadai 4 Kanker Ganas Pembunuh Wanita. Jogjakarta: CV. Andi Offset.

7. Suryaningsih,E.K.danSukaca,2009.KupasTuntasKankerPayudara.Yogyakarta:P aradigma Indonesia 